\title{
The size and prevalence of the cavum septum pellucidum are normal in subjects with panic disorder
}

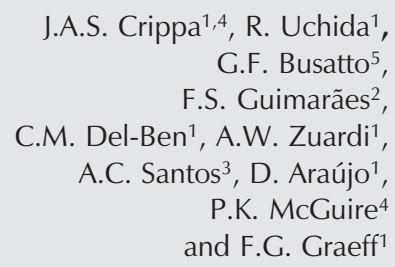

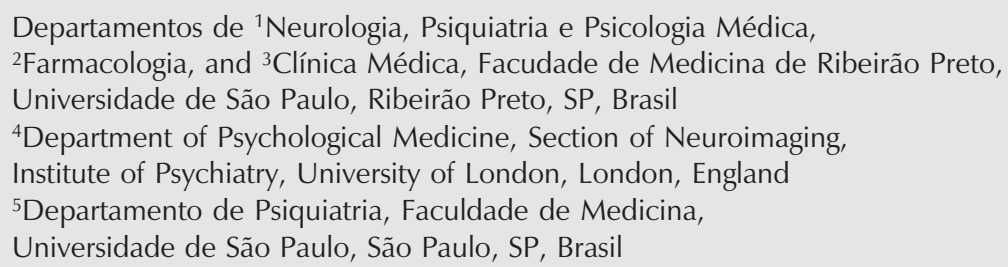

Departamentos de ${ }^{1}$ Neurologia, Psiquiatria e Psicologia Médica, ${ }^{2}$ Farmacologia, and ${ }^{3}$ Clínica Médica, Facudade de Medicina de Ribeirão Preto, Universidade de São Paulo, Ribeirão Preto, SP, Brasil ${ }^{4}$ Department of Psychological Medicine, Section of Neuroimaging, Institute of Psychiatry, University of London, London, England ${ }^{5}$ Departamento de Psiquiatria, Faculdade de Medicina, Universidade de São Paulo, São Paulo, SP, Brasil

\author{
Correspondence \\ J.A.S. Crippa \\ Departmento de Neurologia, \\ Psiquiatria e Psicologia Médica \\ FMRP, USP \\ Av. Bandeirantes, 3900 \\ 14049-900 Ribeirão Preto, SP \\ Brasil \\ Fax: +55-16-635-0713 \\ E-mail: jcrippa@directnet.com.br \\ Research supported in part by \\ FAPESP (Nos. 98/10639-7, \\ 99/12205-7 and 02/13197-2). \\ J.A.S. Crippa is the recipient of \\ CNPq (No. 200984/01-2; 2002-2003) \\ and CAPES (Programa de Absorção \\ Temporária de Doutores, 2003-2007) \\ fellowships. A.W. Zuardi and \\ F.G. Graeff are recipients of $\mathrm{CNPq}$ \\ productivity fellowships (Nos. \\ 303770/85-6 and 300577/1980-0, \\ respectively). F.G. Graeff is the \\ recipient of a research fellowship \\ from FAEPA (No. 67/2002).
}

Received May 30, 2003

Accepted December 1, 2003

$\ldots \ldots \ldots \ldots \ldots \ldots \ldots$

\begin{abstract}
Panic disorder is thought to involve dysfunction in the septohippocampal system, and the presence of a cavum septum pellucidum might indicate the aberrant development of this system. We compared the prevalence and size of cavum septum pellucidum in 21 patients with panic disorder and in 21 healthy controls by magnetic resonance imaging. The length of the cavum septum pellucidum was measured by counting the number of consecutive 1-mm coronal slices in which it appeared. A cavum septum pellucidum of $>6 \mathrm{~mm}$ in length was rated as large. There was no significant difference in the proportion of patients (16 of 21 or $76.2 \%$ ) and controls (18 of 21 or $85.7 \%$ ) with a cavum septum pellucidum ( $\mathrm{P}=0.35$, Fisher's exact test, one-tailed), and no members of either group had a large cavum septum pellucidum. The mean cavum septum pellucidum rating in the patient and control groups was $1.81(\mathrm{SD}=1.50)$ and $2.09(\mathrm{SD}=1.51)$, respectively. There were also no significant differences between groups when we analyzed cavum septum pellucidum ratings as a continuous variable $(\mathrm{U}=$ 196.5; $\mathrm{P}=0.54)$. Across all subjects there was a trend towards a higher prevalence of cavum septum pellucidum in males $(100 \%, 10$ of 10$)$ than females $(75 \%, 24$ of 32; P = 0.09, Fisher's exact test, one-tailed). Thus, we conclude that, while panic disorder may involve septohippocampal dysfunction, it is not associated with an increased prevalence or size of the cavum septum pellucidum.
\end{abstract}

The septohippocampal system (SHS) plays a crucial role in the modulation of anxiety (1). The septum pellucidum, which is part of the SHS, is a thin plate of two laminae that forms the medial walls of the lateral ventricles. When these laminae fail to fuse they form a cavity known as cavum
Key words

- Cavum septum pellucidum

- Panic disorder

- Neuroimaging

- Magnetic resonance imaging septum pellucidum (CSP). The incidence of CSP among normal populations varies greatly, though there is some consensus that very small CSP are common (60-80\% incidence) and part of normal anatomy (2).

It has been suggested that the CSP may be regarded as a developmental anomaly, par- 
ticularly if it is large (3). Thus, a reportedly increased prevalence of CSP in schizophrenia (2) and in post-traumatic stress disorder (4) has been interpreted as evidence that these are neurodevelopmental disorders. However, the clinical significance of a CSP has not been well defined, and the relationship between CSP and neuropsychiatric dysfunction remains unclear.

CSP is of particular interest in panic disorder (PD) because of the putative role of the SHS in its pathophysiology. Moreover, a recent magnetic resonance imaging (MRI) study reported that patients with PD show abnormalities of the septum pellucidum (5), although the data were assessed using qualitative methods.

We used MRI to examine the prevalence and size of CSP in matched groups of patients with PD and controls using quantitative methods. In this study, we hypothesized that PD patients would have a higher incidence and size of CSP than controls.

We studied 21 patients ( 5 men and 16 women) with PD diagnosed using the Portuguese version (6) of the Structured Clinical

\begin{tabular}{|c|c|c|}
\hline Characteristic & Patients & Controls \\
\hline Age (years) & $38.9 \pm 11.0$ & $38.3 \pm 10.0$ \\
\hline \multicolumn{3}{|l|}{ Sex } \\
\hline Male & 5 & 5 \\
\hline Female & 16 & 16 \\
\hline \multicolumn{3}{|l|}{ Handedness } \\
\hline Right & 20 & 21 \\
\hline Left & 1 & 0 \\
\hline Education (years) & $9.8 \pm 4.3$ & $8.5 \pm 3.3$ \\
\hline \multicolumn{3}{|c|}{ Socioeconomic status } \\
\hline Subjects & $2.43 \pm 0.93$ & $2.24 \pm 0.77$ \\
\hline Parents & $2.62 \pm 0.97$ & $2.81 \pm 1.03$ \\
\hline
\end{tabular}

Data are reported as means \pm SD for $N=21$ in each group. Handedness was assessed by the Edinburgh Inventory (9). Classification of socioeconomic status was based on the modified Critério de Classificação Sócio-Econômica Brasil (10). The lower the number, the higher the socioeconomic level.
Interview for DSM-IV (7). They were recruited from outpatient clinics of the University Hospital of the Faculty of Medicine of Ribeirão Preto, Brazil. The mean age of illness onset was 31.1 years $(\mathrm{SD}=10.8)$, the mean illness duration was 7.9 years $(\mathrm{SD}=$ 6.4), and the mean length of pharmacological treatment was 2.1 years $(\mathrm{SD}=3.5)$. Thirteen patients $(61.9 \%)$ also had agoraphobia and $15(71.4 \%)$ had a past history of affective disorder (13 with major depression, 2 with dysthymia) and 4 had mitral valve prolapse. Fifteen patients were receiving antidepressants (selective serotonin reuptake inhibitors in 8 patients, tricyclics in 7) and 5 were receiving adjunctive benzodiazepines. Psychosocial functioning was evaluated using the Global Assessment of Functioning (GAF) instrument (8).

A healthy control group $(\mathrm{N}=21)$ with the same gender distribution (5 men and 16 women) was recruited from the local community. The subjects were matched with the PD group for age, handedness (9), years of education and both personal and parental socioeconomic level (10) (Table 1). Neither controls nor their first-degree relatives had a history of neurological or psychiatric illness. No subjects in either group had a history of head trauma, electroconvulsive therapy, major medical illnesses, or substance abuse. The Ethics Committee of the University Hospital, Faculty of Medicine of Ribeirão Preto, University of São Paulo, approved the present study. All subjects signed an informed consent statement.

$\mathrm{T}_{1}$-weighted images were acquired in the sagittal plane in $1.0-\mathrm{mm}$ thick slices with a 1.5 Tesla MR camera (Magneton Vision, Siemens, Erlangen, Germany) using a threedimensional fast low angle shot protocol $\left(\mathrm{TE}=4 \mathrm{~ms}, \mathrm{TR}=9.7 \mathrm{~ms}\right.$, flip angle $=12^{\circ}$, number of excitations $=1$, field of view $=$ $25.6 \mathrm{~cm}$, matrix $=256 \times 256$ ). The resulting brain volumes were reformatted into $1-\mathrm{mm}$ coronal sections perpendicular to the ACPC plane, and contiguous slices through the 
entire septum pellucidum were selected. Hard copies of the films from both patients and controls were blindly assessed by two independent raters (J.A.S.C. and D.A.J.) experienced in assessing neuroradiological anomalies. The CSP was rated by the number of 1$\mathrm{mm}$ slices in which it was visualized: 0 for absent, 1 for one slice, 2 for two slices and so on $(2,11)$. Since the images were 1-mm thick without gaps, the rating reflected the actual anterior-to-posterior length of the CSP. CSPs spanning 6 or more slices were defined as large (12). A CSP visualized in 1 or more slices was defined as present $(2,11)$. The interclass correlation coefficient for interrater reliability was 0.98 , obtained using the 42 subjects in this study and an additional sample of 38 patients with schizophrenia and 38 healthy controls. In the few instances in which the raters' assessments were not the same by more than 1 point, images were reinspected by both raters together and a consensus rating was made.

Chi-square tests, or Fisher's exact tests when expected cell sizes were less then five, were used for statistical analysis of CSP frequency. Mann-Whitney U-tests were performed to evaluate differences in CSP ratings between PD patients and healthy controls. Correlations between CSP ratings and clinical variables were assessed by Spearman's rank-order coefficient.

There was no significant difference in the proportion of patients ( 16 of 21 or $76.2 \%$ ) and controls (18 of 21 or $85.7 \%$ ) with a CSP $(\mathrm{P}=0.35$, Fisher's exact test, one-tailed). The mean CSP rating in the patient and control groups was $1.81(\mathrm{SD}=1.50)$ and $2.09(\mathrm{SD}=1.51)$, respectively. There were also no significant differences between groups when we analyzed CSP ratings as a continuous variable $(\mathrm{U}=196.5 ; \mathrm{P}=0.54)$. All male subjects in both groups had a CSP, whereas in females the frequency was $81.3 \%$ (13 of 16) in the PD group and 68.8\% (11 of $16)$ in healthy controls ( $P=0.34$, Fisher's exact test, one-tailed). There were no male- female differences in the prevalence of the CSP within either the PD group ( $\mathrm{P}=0.22$, Fisher's exact test, one-tailed) or the healthy control group ( $\mathrm{P}=0.42$, Fisher's exact test, one-tailed), and no significant differences between patients and controls when the comparisons were restricted to either male or female subjects. However, when the two groups were pooled together, a trend emerged towards a higher prevalence of CSP in male $(100 \%, 10$ of 10$)$ than female subjects $(75 \%$, 24 of 32; $\mathrm{P}=0.09$, Fisher's exact test, onetailed). No subject in either group had a large CSP.

Within the PD group, there were no significant correlations between CSP ratings and age at disease onset $(\mathrm{r}=-0.27, \mathrm{P}=0.24$, $\mathrm{N}=21)$, duration of illness $(\mathrm{r}=0.18, \mathrm{P}=$ $0.43, \mathrm{~N}=21)$, length of treatment $(\mathrm{r}=0.12$, $\mathrm{P}=0.61, \mathrm{~N}=21)$, or GAF score $(\mathrm{r}=-0.07$, $\mathrm{P}=0.75, \mathrm{~N}=21)$. Across all subjects pooled together there was no correlation between CSP ratings and age $(\mathrm{r}=0.05, \mathrm{P}=0.75, \mathrm{~N}=$ 42), years of education ( $r=0.17, P=0.28$, $\mathrm{N}=42)$, socioeconomic status $(\mathrm{r}=-0.16, \mathrm{P}=$ $0.30, \mathrm{~N}=42)$, or parental socioeconomic status ( $\mathrm{r}=-0.15, \mathrm{P}=0.33, \mathrm{~N}=42)$.

There were no significant differences between patients with affective disorder and patients without affective disorder in gender, age, years of education, age at disease onset, duration of illness, length of treatment, GAF score, and CSP presence or size.

Although we hypothesized that the PD patients would have a higher frequency and severity of CSP than controls, no difference was found. This contrasts with the findings of Dantendorfer et al. (5), and may reflect our use of a quantitative rather than qualitative method of assessment (2). It may also be related to differences in the respective patient populations studied; for example, all the patients with a CSP in the study by Dantendorfer et al. (5) had EEG abnormalities. It is also possible that our results could be explained by our relatively small sample size. 
One important limitation of the interpretation of our results is that many of our patients had depressive disorder in addition to PD. Nevertheless, this did not seem to affect the frequency or severity of CSP, since there were no differences between patients with and without affective disorder. Moreover, no previous MRI studies of affective disorders have reported higher frequency or severity of CSP in depressive patients relative to controls (13-15).

The prevalence of CSP in the control group $(85.7 \%)$ observed in the present study is amongst the highest in the literature, but similar to that reported in other MRI studies that used thin slices, and in post-mortem studies $(12,15)$. These findings support the notion that a small CSP is common in controls and reflects normal anatomical variation (2). For all subjects there was a trend towards a higher incidence of CSP in male compared to female subjects, consistent with previous observations $(2,13,15)$.

The present results do not demonstrate differences in either CSP size or incidence between PD patients and healthy controls.

\section{References}

1. Gray JA \& MacNaughton N (2000). The Neuropsychology of Anxiety. An Enquiry into the Functions of the Septo-Hippocampal System. 2nd edn. Oxford University Press, Oxford, UK.

2. Nopoulos P, Swayze V, Flaum M, Ehrhardt JC, Yuh WT \& Andreasen NC (1997). Cavum septi pellucidi in normals and patients with schizophrenia as detected by magnetic resonance imaging. Biological Psychiatry, 41: 1102-1108.

3. Sarwar M (1989). The septum pellucidum: normal and abnormal. American Journal of Neuroradiology, 10: 989-1005.

4. Myslobodsky MS, Glicksohn J, Singer J, Stern M, Bar-Ziv J, Friedland N \& Bleich A (1995). Changes of brain anatomy in patients with posttraumatic stress disorder: a pilot magnetic resonance imaging study. Psychiatry Research, 58: 259-264.

5. Dantendorfer K, Prayer D, Kramer J et al. (1996). High frequency of EEG and MRI brain abnormalities in panic disorder. Psychiatry Research: Neuroimaging, 68: 41-53.

6. Del-Ben CM, Vilela JAA, Crippa JAS, Hallak JEC, Labate CM \& Zuardi AW (2001). Confiabilidade da "Entrevista Clínica Estruturada para o DSM-IV - Versão Clínica" traduzida para o português [Testretest reliability of the Structured Clinical Interview for DSM-IV Clinical Version (SCID-CV) translated into Portuguese]. Revista Brasileira de Psiquiatria, 23: 156-159.

7. First MB, Spitzer RL, Gibbon M \& Williams JBW (1997). Structured Clinical Interview for DSM-IV Axis I Disorders (SCID), Clinician Version. American Psychiatric Press, Washington, DC, USA.

8. American Psychiatric Association (1994). Diagnostic and Statistical Manual of Mental Disorders. 4th edn., revised. APA Press, Wash- ington, DC, USA.

9. Oldfield RC (1971). The assessment and analysis of handedness: The Edinburgh Inventory. Neuropsychologia, 9: 97-113.

10. Associação Brasileira dos Institutos de Pesquisa de Mercado (1997). Critério de Classificação Sócio-Econômica Brasil. ABIPEME, São Paulo, SP, Brazil.

11. Nopoulos PC, Giedd JN, Andreasen NC \& Rapoport JL (1998) Frequency and severity of enlarged cavum septi pellucidi in childhood-onset schizophrenia. American Journal of Psychiatry, 155: 1074-1079

12. Hagino H, Suzuki M, Kurokawa K, Mori K, Nohara S, Takahashi T, Yamashita I, Yotsutsuji T, Kurachi M \& Seto H (2001). Magnetic resonance imaging study of the cavum septi pellucidi in patients with schizophrenia. American Journal of Psychiatry, 158: 17171719 .

13. Jurjus GJ, Nasrallah HA, Olson SC \& Schwarzkopf SB (1993). Cavum septum pellucidum in schizophrenia, affective disorder and healthy controls: a magnetic resonance imaging study. Psychological Medicine, 23: 319-322.

14. Shioiri T, Oshitani $Y$, Kato T, Murashita J, Hamakawa H, Inubushi T, Nagata T \& Takahashi S (1996). Prevalence of cavum septum pellucidum detected by $\mathrm{MRI}$ in patients with bipolar disorder, major depression and schizophrenia. Psychological Medicine, 26: 431434.

15. Kwon JS, Shenton ME, Hirayasu Y et al. (1998). MRI study of cavum septi pellucidi in schizophrenia, affective disorder, and schizotypal personality disorder. American Journal of Psychiatry, 155: 509-515. 